\title{
Chondroma in an Indian ring neck parrot (Psittacula krameri manillensis): A case report
}

\author{
Debasish Behera ${ }^{1}$, Deepak Kumar ${ }^{2}$, Ashabaree Samal $^{3}$ and S. K. Panda ${ }^{4}$ \\ 1.Department of Veterinary Pathology, College of Veterinary Sciences and Animal Husbandry, R.K. Nagar, \\ Agartala-799008, Tripura (West), India; 2.Department of Veterinary Public Health \& Epidemiology, College of Veterinary \\ Sciences and Animal Husbandry, R.K. Nagar, Agartala-799008, Tripura (West), India; 3.Division of Bacteriology \& \\ Mycology, IVRI, Izatnagar, Bareilly, Uttar Pradesh, India; 4.Department of Veterinary Pathology, College of Veterinary \\ Science and Animal Husbandry, OUAT, Bhubaneswar, Odisha, India \\ Corresponding author: Debasish Behera, email: behera.debasish1@gmail.com \\ Received: 13-07-2012, Accepted: 11-08-2012, Published online: 19-01-2013
}

How to cite this article:

Behera D, Kumar D, Samal A and Panda SK (2013) Chondroma in an Indian ring neck parrot (Psittacula krameri manillensis): A case report, Vet. World 6(4): 223-225, doi: 10.5455/vetworld.2013.223-225

\section{I ntroduction}

Chondroma is a benign neoplasm arising from the cartilaginous tissue [1]. This term is also used to describe any benign proliferation of the cartilage, such as extra skeleton chondroma from mixed tumours of mammary gland of dog, synovial and bursal chondroma, osteochondroma, ecchondroma and many non classified bone chondromas $[2,3]$. There are very few reports of neoplastic cases including chondroma in wild birds [4]. The present communication placed on record a rare case of the chondroma affecting the right metacarpal of an Indian ring neck parrot and its successful surgical management. The gross and histopathological studies were carried out to ascertain the pathogenesis and type of neoplastic growth.

\section{Case history}

A young Indian ring neck parrot, weighing $400 \mathrm{~g}$ was presented to the Teaching Veterinary Clinical Complex, College of Veterinary Science and Animal Husbandry, Bhubaneswar, with the complaint of tumour like growth in the right wing. The bird was being kept under captivity by a resident of Bhubaneswar. Further anamnesis revealed a tumour like growth over the right metacarpal region of the wing (Fig.1). It was firm, roughly circular and the covering skin was rough and uneven probably due to atrophy. Symptoms were inability to fly, progressive weakness with partial anorexia demanding surgical intervention. The tumour mass was excised with local anaesthesia and was kept in $10 \%$ formal saline for further histological analysis.

\section{Clinical examination and treatment}

The bird was not co-operative for detailed clinical observation and pre-operative preparation. So it was properly restrained before surgery. The operation site was prepared for surgical intervention by taking all the aseptic precautions. Local infiltration of $2 \%$ Lignocaine $\mathrm{HCl}$ (Wocaine 2\%, Wockhardt, India) around the tumour mass was done to achieve the local anaesthesia. An elliptical incision was made all around the base of the growth. The growth was completely removed and the haemostasis was achieved by electrocautery. The surgical incision was closed as per standard technique. The weight of the tumour mass was $75 \mathrm{~g}$ with radius of $2 \mathrm{~cm}$. Post-operatively, a broad spectrum antibiotic (Cephalosporin @ $50 \mathrm{mg} / \mathrm{kg}$ ) was administered intramuscularly (breast muscle) for 5 days. Daily dressing of the surgical wound was done with antiseptic ointment (Himax, IH). The bird recovered uneventfully within two weeks. There was no recurrence of the growth in a follow-up period of three months.

Tumour was cut in to $1 \mathrm{~cm}^{3}$ pieces, fixed in $10 \%$ formalin solution and processed for histopathological examination following the standard procedure [5]. Thereafter, the tissue was processed using the routine technique and 4-5 $\mu$ thick tissue sections were stained by $\mathrm{H} \& \mathrm{E}$ staining method. Histopathological analysis revealed a non capsulated neo-plastic tissue of mesenchymal origin formed by chrondro-blasts and chrondocytes. It was surrounded by connective tissues (Fig. 2). Cellular pleomorphism was not very evident. Chrondrocytes were well differentiated with prominent nuclei and nucleoli (Fig.3). No mitosis of the cells could be identified. Inflammatory infiltration consisted of mononuclear cells and heterophils surrounding cartilaginous neoplastic cells (Fig.4). Interstitial haemorrhage was also observed. (Fig. 5).

\section{Discussion}

Usually, Chondromas grow slowly and the clinical signs are associated with the size and localization of the neoplasm. Grossly, chondromas are variable in size, firm and surrounded by a fibrous capsule displaying a whitish discolouration, which is also evident in this study. Chondromas are distinguished from chondrosarcomas or malignant form by lack of local invasiveness, more orderly arrangement of cartilage cells and closer resemblance to normal mature cartilage [6]. These findings are completely in accordance with our record. The surrounding skin showed atrophy, ulceration and suppurative exudation due to extensive growth. In a similar work, a non capsulated neoplastic tissue of mesenchymal origin formed by chrondroblasts and chrondocytes and surrounded by connective tissues with or without cellular pleomorphism, well differentiated 


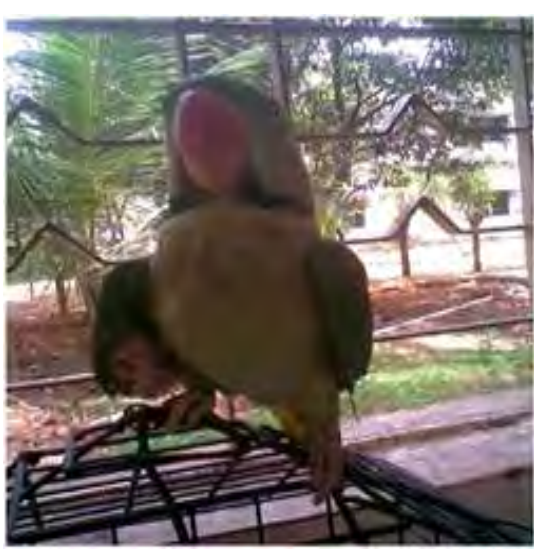

Figure-1. Tumour mass at the right metacarpus of an Indian ring neck parrot (Psittacula krameri manillensis)

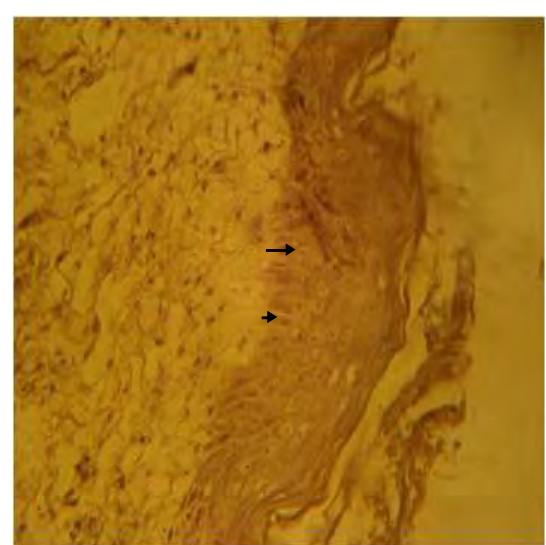

Figure- 2. Chrondroblasts and chrondrocytes and surrounded by Connective tissues, Chondroma, right metacarpal region, $\mathrm{HE}$ stains $(x 40)$.

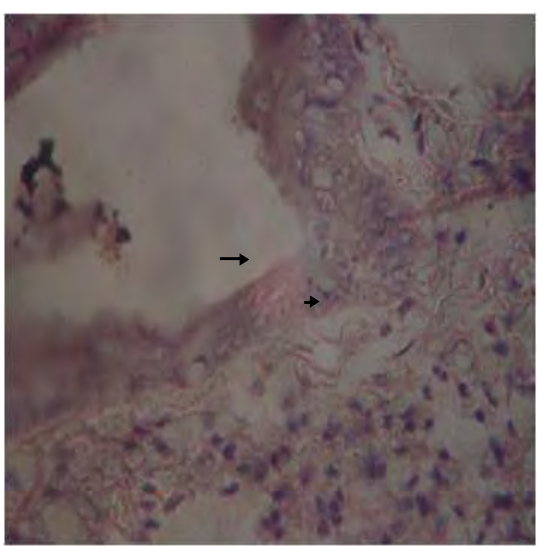

Figure-4. Inflammatory infiltration consisted by mononuclear cells and heterophils surrounding cartilaginous neoplastic cells, HE stains ( $x$ 100).

chrondrocytes having well defined nuclei, nucleoli, no mitotic changes of the cells was reported [7]. These Histologic characters have shown the remarkable similarities with our findings. The histological examination revealed that the mass was divided into lobules by a thin fibrous stroma. The neoplastic cells were uniform in shape and size, and they were composed of well-differentiated mature chrondrocytes with poorly vascularized areas [8]. These findings are in complete accordance with our results.

Differences between chondroma and malignant cartilaginous neoplasm are not always clearly identified; there are some transitional tumours and neoplastic processes believed to be benign might acquire malignant characteristics. However, our investigation revealed only benign form of chondroma and the tumour mass was limited to the radius ulna and metacarpal region. In an incidence study, 13 mesenchymal tumours on the plantar aspects of the foot-pads of Anseriformes and wild Mallards were reported [4]. The larger nodules had superficial ulcerations and haemorrhage. Single nodular chondromas were found on the proximal humerus of a pacific gull and attached to the cranium of three canaries [4].

In a similar study, Howard and co-workers (1996) reported a case of synovial chondromatosis in a great

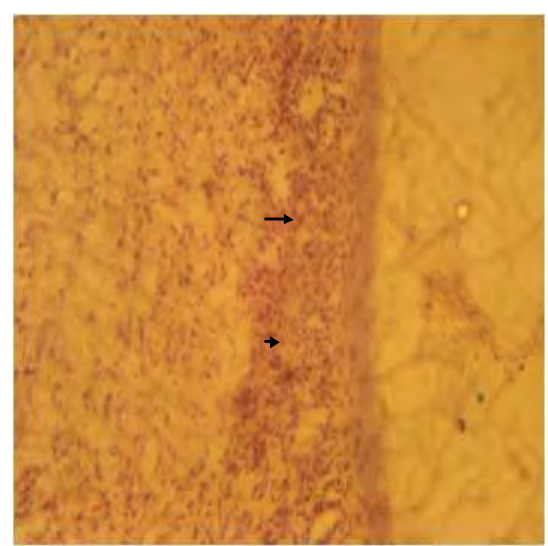

Figure - 5. Interstitial haemorrhage with inflammatory cells infiltration, Chondroma of Metacarpus, HE stains (x 40).

horned owl (Bubo virginianus) with bilateral swelling of the scapulohumeral joint characterized by the formation of multiple, benign cartilaginous nodules in the synovium [9]. In humans, most cases of chondromatosis involve the knee, joints of the shoulder, carpal and tarsal bones, ankle and mandible [10]. Forrester and Spalding described multiple cutaneous chondromas and chondrosarcomas on the legs of free-flying Sandhill (Grus canadensis) and Whooping Cranes (Grus americana) [11]. Unlike wild birds, chondroma has been frequently reported in domestic animals. In a recent study, a chondroma of the vertical ramus of the mandible in feline species was reported [12]. Similar to our study no reoccurrence was observed after surgery. In another report, Mohammed described benign cartilaginous tumor in a 3.5 year-old ewe [13]. Contoured borders were covered by fibrous tissue capsule as observed in the present study [13].

Chondromas have already been frequently reported in domestic animals. However, neoplasms arising from the cartilage are very rare in wild birds. Here we report an infrequent case of chondroma in an Indian Ring Neck Parrot (Psittacula krameri manillensis) and its gross and histologic lesions were well supported by different workers. To the best of our knowledge, this is probably the first clinical and pathological description of 
chondroma in Indian Ring Neck Parrot.

\section{Conclusion}

In the present case study, successful surgical management of the chondroma involving the wing of the Indian Ring Neck Parrot and its gross and histopathologic findings have been reported. However, a little information regarding this type of neoplastic condition is available in the current literatures. The pathomorphological characteristics seen in the present case suggesting that this tumour represents a rare report of chondroma in wild birds. The surgical excision with post operative care could be useful for complete recovery in cases of chondroma in birds.

\section{References}

1. Vegad, J. L. (2007) Veterinary General Pathology. $2^{\text {nd }}$ edn, IBDC, Publishing Division, Lucknow, UP, India, pp.278.

2. Thomson, R. G. (1989) Special Veterinary Pathology. $1^{\text {st }}$ Indian Edition, CBS Publishers and Distributers, New Delhi.

3. Moulton, J.E. (1990) Tumours in Domestic Animals. University of California Press, Los Angeles, Pp.173-174.

4. Reece, R. L. (1992) Observations on naturally occurring neoplasms in birds in the state of Victoria, Australia. Avian Pathology, 21:1,3-32.

5. Luna, LG. (1968) Manual of Histologic Staining Methods of the Armed forces Institute of Pathology, $3^{\text {rd }}$ Ed., McGrawHill, New York.

6. Jones, T. C., and Hunt, R. D. (1983) Veterinary Pathology. Fifth Edition, Lea \& Febiger, 600 Washington Square, Philadelphia, USA, pp.1202.

7. Rego, A. A. M. da Silva, Matushima E. R. and Miguel M. C. (1999) Chondroma in rufescent tiger-heron (Tigrisoma lineatum): case report. Braz. J. Vet. Res. Anim. Sci., São Paulo, vol.36 n.1.

8. Haziroglu, R., Bilgili, H. and Kapakin, K.A.T. (2007) Chondroma in a dog. Turkish Journal of Veterinary and Animal Sciences. 31(1): 79-81.

9. Howard, M.O., Nieves, M. A. and Miles, K.G. (1996) Synovial Chondromatosis in a Great Horned Owl (Bubo virginianus). Journal of wildlife Diseases, 32 (2): 370-372.

10. Fechner, R.E. and Mills, S.E. (1992) Tumors of the bones and joints. In Atlas of tumor pathology, $3^{\text {rd }}$ series, Fascicle 8., J. Rosai and L.H. Sobin (eds.). Armed Forces Institute of Pathology, Washington, D.C., pp. 279-282.

11. Forrester, D.J., and Spalding, M.G. (2003) Parasites and disease of wild birds in Florida. Univesrity Press of Florids, Gainesville, Florida. pp. 1132.

12. Hodik, V., Loeb, E and Ranen, E. (2012) Chondroma of the vertical ramus of the feline mandible. Journal of Feline Medicine and Surgery. doi: 10.1177/1098612X12451697.

13. Mohamed, A.F. (2011) Benign Cartilaginous Tumor in a Sheep: Clinical and Histopathological Findings. Journal of Agricultural and Veterinary Sciences. 4 (1): 61-66.

$* * * * * * * *$ 